\title{
Satisfaction among early and mid-career dentists in a metropolitan dental hospital in China
}

\begin{abstract}
Xiaoxi Cui'
David G Dunning ${ }^{2}$

$\mathrm{Na} \mathrm{An}^{3}$

'College of Dentistry, University of Nebraska Medical Center, Lincoln, NE, USA; ${ }^{2}$ Department of Oral Biology, College of Dentistry, University of Nebraska Medical Center, Lincoln, NE, USA; ${ }^{3}$ chool of Stomatology, Department of General Dentistry II, Peking University School and Hospital of Stomatology, Beijing, People's Republic of China
\end{abstract}

\section{Video abstract}

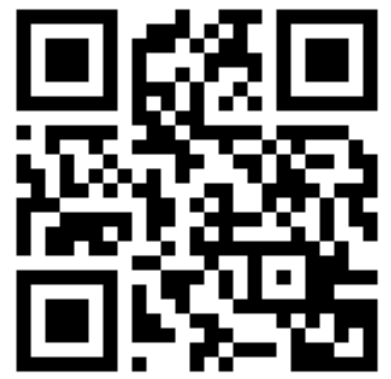

Point your SmartPhone at the code above. If you have a QR code reader the video abstract will appear. Or use: http://youtu.be/R04TZT7UF5A

Correspondence: David G Dunning College of Dentistry, Department of Oral Biology, University of Nebraska Medical Center, 4000 East Campus Loop South/I I29, Lincoln, NE 68583, USA

Tel + I 402472 I 325

Fax + I 402472255 I

Email ddunning@unmc.edu

$\mathrm{Na}$ An

School of Stomatology, Department of General Dentistry II, Peking University School and Hospital of Stomatology, Beijing, People's Republic of China

Email anna@pkuss.bjmu.edu.cn
This article was published in the following Dove Press journal:

Journal of Healthcare Leadership

6 June 2017

Number of times this article has been viewed

Abstract: A growing body of research has examined career satisfaction among dentists using a standardized instrument, dentist satisfaction survey (DSS). This project examined career satisfaction of early to mid-career dentists in China, a population whose career satisfaction, heretofore, has not been studied. This is an especially critical time to examine career satisfaction because of health care reform measures being implemented in China. A culturally sensitive Chinese-language version of the DSS (CDSS) was developed and electronically administered to 367 early and mid-career dentists in a tertiary dental hospital in Beijing, China. One hundred and seventy respondents completed the survey. The average total career score was 123 , with a range of 82-157. Data analysis showed some significant differences in total career score and several subscales based on gender, working hours per week, and years in practice. A stepwise regression model revealed that two variables predicted total career score: working hours per week and gender. Stepwise regression also demonstrated that four subscales significantly predicted the overall professional satisfaction subscale score: respect, delivery of care, income and patient relations. Implications of these results are discussed in light of the health care delivery system and dentist career paths in China.

Keywords: job satisfaction, career satisfaction, early and mid-career dentists, Chinese health care reform

\section{Plain language summary}

A number of studies in many countries have examined the level of job/career satisfaction of dentists. In general, dentists have a moderate to high level of job/career satisfaction. This study aimed to close a gap in the research by assessing the job/career satisfaction of early and midcareer dentists in China working in Beijing's large, metropolitan dental school. China's health care system is undergoing reform, and thus this was a good time to check on the job/career satisfaction of dentists. Chinese dentists' total career satisfaction score was moderately high, a result fairly consistent with other studies. Several differences based on demographics were noted in the total score and individual scales making up the total score. Most notably, female dentists and dentists working 21-40 hours per week (vs $>40$ hours per week) had higher total satisfaction scores and higher scores on a few individual scales, including personal time, professional environment, and overall professional satisfaction. Results of the study are discussed in light of previous research, and applications are made to health care reform and leadership.

\section{Review of literature/introduction}

Job satisfaction has been described as a "positive emotional state resulting from the appraisal of one's job or job experience." A dentist's career satisfaction impacts a dentist's performance. It is also closely related to general life satisfaction, as they 
both reciprocally contribute to an individual's happiness and overall well-being in the community. ${ }^{2,3}$

Studies have focused on job satisfaction of dentists, which have been conducted in many countries and a variety of variables have been studied. Most of the earlier studies used well-structured questionnaires, which measured both overall job satisfaction and satisfaction with different facets in dentistry. In the USA, one comprehensive and well-known analysis of job satisfaction in dentistry was conducted by Shugars et al. ${ }^{1}$ The study used the dentist satisfaction survey (DSS). The results showed 58\% of the variance in overall job satisfaction was explained by nonwork life quality and five facets of the profession including respect, delivering care, income, relationships with patients, and stress. Another study of job satisfaction among Canadian orthodontists showed the most satisfied dentists were older, reported higher incomes, attended more continuing education, and employed more dental auxiliaries; in contrast, dentists were most dissatisfied with the threat of malpractice, level of income, demands of managing the practice, and amount of personal time. ${ }^{4,5}$

Several studies on job satisfaction among dentists have been done in European countries as well. In the UK, since there is a different health care system from the USA, more comparison was done among different groups of dental care providers. One study measured levels of work pressure, job satisfaction, and other factors related to occupational stress in community dental service staff in north Wales in $1993 .^{6}$ The community dental service staff showed poor levels of job satisfaction and psychosomatic indicators of stress. The perception of control of the individual's working practices was highly influenced by organizational demands. Harris et al conducted a study comparing facets of job satisfaction for practitioners working in the different organizational settings of personal dental services (PDS) practices (NHS personal dental service), general dental services (GDS) practices (NHS general dental service), and practices where there was a mix of NHS and private provision. ${ }^{7}$ An 83 -item questionnaire including questions from the DSS was used. Results showed GDS dentists working fully in the NHS were least likely to be satisfied with their jobs, followed by PDS practitioners, and then GDS dentists working in mixed NHS/ private practices. Private practitioners were the most satisfied. A similar result was seen in a study in Macedonia - namely, significant differences related to working conditions were found between public practitioners (moderately dissatisfied) and private practitioners (very satisfied). ${ }^{8}$ In the Netherlands, the relationship between Dentist Job Satisfaction Scale and Dentists' Experienced Job Resources Scale was analyzed. ${ }^{9}$ In this study, dentists reported these as the most rewarding job aspects: seeing immediate results, a focus on aesthetics, and long-term results of working with patients. All job resources showed a positive correlation with job satisfaction. Another cross-sectional survey on job satisfaction in Turkey identified these significant factors related to overall satisfaction: age, the type of social insurance possessed, income level, the presence of dental auxiliaries, and the number of patients examined per day. ${ }^{10}$ In Germany, a study showed that dentists were satisfied with "freedom of working method" and mostly dissatisfied with their "income". Both variables are extrinsic factors. ${ }^{11}$ And one Lithuanian survey indicated self-perceived lack of self-esteem, loneliness and, especially, depression had a high negative impact on dentists' job satisfaction. Increasing age significantly reduced the possibility of nervousness or depression and also increased the possibility of being satisfied with dental practice. ${ }^{12}$

In Australia, New Zealand, and some Asian countries, research about job satisfaction among dentists have also been published in the past years. Several studies in Australia showed that the majority of dentists who responded to the surveys were satisfied with their current dental job. ${ }^{2,13,14}$ Differences existed between private and public dentists, metropolitan and nonmetropolitan dentists, male and female dentists, and dentists of different ages. Workplaces that offer job autonomy, competitive pay, flexible working hours, and minimal administrative burden may improve dentist job satisfaction. A study in New Zealand comparing gender differences in dentists' working practices and job satisfaction indicated that male dentists were generally more satisfied than female dentists. ${ }^{15}$ In 2006, Jeong et al measured job satisfaction among registered dentists in South Korea using a modified version of the DSS. The study showed that the mean score of overall job satisfaction among South Korean dentists was 3.2 out of $5 .{ }^{16}$ Patient relations, perception of income, personal time, staff, and specialty training are important work environment factors for job satisfaction among South Korean dentists. Another study also using a modified version of DSS conducted among 66 registered dentists in India showed a mean score of overall job satisfaction among dentists was 3.08 out of $5 .{ }^{17}$ The most satisfying aspect was income (3.7) and the least satisfying aspect was staff (2.5).

Dental care in China is predominantly government financed with the majority of dentists working in public hospitals, although there are increasingly more private practitioners. In 2009, the Chinese government published a foundational document driving the health care system: "Guidelines on Deepening the Reform of the Health Care System." This 
document focused on providing "safe, effective, convenient, and affordable" health care services for all citizens by $2020 .{ }^{18}$ During the process of the reform, numerous changes have been made and dental care has been affected in many aspects as well. Some major changes of dentistry in China include new basic health insurance coverage, more market-oriented private practice and multi-sited licensure. These changes raise many questions. One of the most fundamental questions is: how satisfied are today's dentists in view of a changing health care environment? To date, no research has focused on the career satisfaction of dentists in China.

Assessing the level of job satisfaction among early and mid-career dentists provides a key barometer of the dental profession in China. Young and mid-career health care providers are most directly impacted by the health reform in the near-term and long-term. They are also in a stage of developing personal habits in professionalism and leadership which will, in turn, help to shape the future changes of the ongoing health reform. Measures of job satisfaction can be used to identify problems or issues that dentists have from their daily work, to monitor the effects of the health care reform, and to educate dental students about the realities of dental practice. The results could also be used to uncover ways to improve dentists' working environment, to counsel the policy makers of the current level of job satisfaction among dentists, and to inform health care reform.

The goals of this study were to: 1) investigate the level and distribution of job satisfaction among early and mid-career Chinese dentists working in the public hospital, 2) examine differences in satisfaction associated with demographic and practice characteristics of the Chinese dentists, and 3) initiate discussions about program and policy implications for improving job satisfaction.

\section{Methods and materials Survey instrument}

The survey instrument, Chinese dentist satisfaction survey (CDSS), was developed based on the DSS, a standardized instrument with established levels of reliability ranging from 0.60 to 0.92 for both the subscales and overall job satisfaction. ${ }^{3}$ The CDSS instrument was transliterated from the DSS with minor modifications made to reflect cultural uniqueness more appropriate for Chinese dentists. A similar approach was successfully utilized in another Asian country. ${ }^{16}$ The CDSS consisted of 38 items: 7 items to measure the factor of overall professional satisfaction and 31 items related to 10 work environment factors. The Supplementary material reproduces the CDSS. Note that negatively phrased items were incorporated into the survey, mirroring the practice of previous studies involving the DSS; negatively worded items are underlined in the Supplementary material. The work environment factors included: perception of staff, income, professional relations, professional time, delivery of care, patient relations, personal time, professional environment, respect, and stress. The 38 instrument items were randomly assigned in the CDSS to yield more reliability results and to manage response bias. All items were measured by a 5-point Likert scale: $1=$ strongly disagree, $2=$ disagree, $3=$ neither agree nor disagree, $4=$ agree, and $5=$ strongly agree. The questionnaire also gathered information about the demographic and practice characteristics of the subjects, including gender, date of birth, hometown (rural or urban area), highest education, specialty training status, years of practice, and working hours per week. The rural/urban carries distinctiveness in the Chinese culture because government issued Household Register clearly denote "rural" versus "urban". The survey was written in both Chinese and English using the online survey software "Sojump". "Sojump" is an online survey system similar to "Survey Monkey" (surveymonkey.com), and Peking University has a subscription to this software. Institutional approval for the projection of human subjects was secured for the survey and entire research protocol from both the University of Nebraska Medical Center (\#495-16-EX) and the Peking University School and Hospital of Stomatology (\#PKUSSIRB-201627035).

\section{Subjects and study design}

The study population consisted of all licensed dentists between 20 and 45 years of age working in a tertiary dental hospital in Beijing, China. The name list of 414 dentists was obtained from the human resources office of the hospital, 367 of whom had available email addresses. The initial emails to all subjects with a cover letter and a link to the online questionnaire were sent to the 367 dentists between December 2016 and January 2017. Follow-up emails were sent 2 and 4 weeks later to the dentists who had not replied to the initial one. Completion of the survey was viewed as informed consent based on the institutionally approved protocol from both universities.

\section{Statistical analyses}

The survey data were collected from the "Sojump" software using Microsoft Excel 2016 (Microsoft, Redmond, WA, USA) and then the entry errors and outlier values were reviewed. Negatively worded responses were reverse-scored so that higher scores represented higher satisfaction or 
attainment. The score of items for each factor were averaged to determine the degree of satisfaction. The average scores of each factor were classified into three categories based on the mean score in line with previous research: ${ }^{4}$ dissatisfied (1.0-2.5), neutral $(>2.5-<3.5)$, and satisfied (3.5-5.0). Total career score was defined as total score of all items. All statistical analyses were conducted using SPSS version 22.0 (SPSS Inc., Armonk, NY, USA). Independent $t$-tests and analysis of variance (ANOVA) were used to compare variables of demographic and practice characteristics. Stepwise multiple regression analysis was used to identify predictors or total career score and its related personal and professional characteristics, and the factor of overall professional satisfaction and its related personal and professional characteristics. $p$ Values $<0.05$ were considered as having statistically significant differences.

\section{Results}

Of the 367 initial emails, 8 were undeliverable. In all, 170 respondents completed the survey, resulting in an adjusted response rate of $47.4 \%$. Table 1 summarizes the descriptive data of the respondents. Of the 359 subjects emailed, 145 (40.4\%) were male and $214(59.6 \%)$ were female. Sixty-four (37.6\%) respondents were male and $106(62.4 \%)$ respondents were female. The gender percentages of respondents were consistent with the total surveyed subjects. The mean age of respondents was 33.17 years with standard deviation of 5.81 . About $29 \%$ of the respondents were from a rural area, $70 \%$ were from urban area. Sixty-one respondents $(35.9 \%)$ reported to have master's or doctor of philosophy degree, and 109 (64.1\%) had completed Doctor of Dental Medicine degree. The majority of the respondents (94.1\%) finished a specialty training program. Eighty-three (48.8\%) respondents had $\leq 5$ years of experience in practice, 45 (26.5\%) with 6-10 years, and the remaining 42 (24.7\%) had $\geq 11$ years of experience in practice. Ninety $(52.9 \%)$ dentists reported working $>40$ hours per week, and 74 (43.5\%) with 21-40 working hours per week (Table 1). Since only six dentists reported working $<20$ hours per week, this group was excluded from statistical analysis.

Table 2 depicts the average total career score, averages on the various subscales of the CDSS, and the distribution based on the three categories of satisfaction on the subscales: dissatisfied, neutral, and satisfied. The mean score of total career score of the respondents was 123.12, with a range of $82-157$, and with a full score of 190 . The top three highest mean score factors were professional relations (3.70), staff (3.66), and respect (3.57). The three factors with lowest mean score were personal time (2.39), income (2.56), and stress (2.66). The majority (50\%) showed neutral with their overall professional satisfaction, $12.4 \%$ of dentists showed dissatisfied, and $37.6 \%$ showed satisfied.

Table I Key descriptive data of survey respondents and results of total career score

\begin{tabular}{|c|c|c|c|c|c|}
\hline Characteristics & $\mathbf{N}(\%)$ & $\begin{array}{l}\text { Mean total } \\
\text { career score (SD) }\end{array}$ & Maximum & Minimum & Range \\
\hline Age (year) & 170 & $33.17^{\mathrm{a}}(5.8 \mathrm{I})$ & & & \\
\hline \multicolumn{6}{|l|}{ Gender } \\
\hline Male & $64(37.6)$ & 119.36 (15.19) & 154 & 87 & 67 \\
\hline Female & $106(62.4)$ & $125.40(\mid 4.55)$ & 157 & 82 & 75 \\
\hline \multicolumn{6}{|l|}{ Birthplace } \\
\hline Rural area & $50(29.4)$ & $124.78(15.12)$ & 157 & 82 & 75 \\
\hline Urban area & $120(70.6)$ & $122.43(\mid 5.01)$ & 156 & 87 & 69 \\
\hline \multicolumn{6}{|l|}{ Highest education } \\
\hline Master and $\mathrm{PhD}$ & $61(35.9)$ & $123.00(13.15)$ & 154 & 90 & 64 \\
\hline DMD & $109(64.1)$ & $123.19(16.06)$ & 157 & 82 & 75 \\
\hline \multicolumn{6}{|l|}{ Specialist training } \\
\hline Yes & $160(94.1)$ & I 22.89 (| 4.98$)$ & 157 & 82 & 75 \\
\hline No & $10(5.9)$ & $126.80(16.38)$ & 154 & 110 & 44 \\
\hline \multicolumn{6}{|l|}{ Years of practice } \\
\hline$\leq 5$ & $83(48.8)$ & $125.83(12.64)$ & 157 & 91 & 66 \\
\hline $6-10$ & $45(26.5)$ & I 18.58 (18.09) & 154 & 82 & 72 \\
\hline$\geq 11$ & $42(24.7)$ & $122.64(14.97)$ & 156 & 90 & 66 \\
\hline \multicolumn{6}{|c|}{ Working hours per week } \\
\hline$\leq 20$ & $6(3.5)$ & I $23.83(7.73)$ & 133 & 113 & 20 \\
\hline $21-40$ & $74(43.5)$ & I $27.07(|2.7|)$ & 156 & 99 & 57 \\
\hline$\geq 40$ & $90(52.9)$ & $119.83(16.42)$ & 157 & 82 & 75 \\
\hline
\end{tabular}

Note: a Mean age of the respondents.

Abbreviation: DMD, Doctor of Dental Medicine. 
Table 2 Rank order of job satisfaction variables based on mean score

\begin{tabular}{|c|c|c|c|c|c|c|c|}
\hline \multirow[t]{2}{*}{ Job satisfaction variables } & \multirow[t]{2}{*}{ Mean (SD) } & \multirow[t]{2}{*}{ Maximum } & \multirow[t]{2}{*}{ Minimum } & \multirow[t]{2}{*}{ Range } & \multicolumn{3}{|c|}{ Distribution $^{a}$ (\%) } \\
\hline & & & & & Dissatisfied & Neutral & Satisfied \\
\hline Total career score ${ }^{\mathrm{b}}$ & $123.12(15.04)$ & 157.00 & 82.00 & 75.00 & & & \\
\hline Professional relations & $3.70(0.95)$ & 5.00 & 1.00 & 4.00 & $27(15.9)$ & $19(11.2)$ & $124(72.9)$ \\
\hline Staff & $3.66(0.75)$ & 5.00 & 1.67 & 3.33 & $16(9.4)$ & $43(25.3)$ & III (65.3) \\
\hline Respect & $3.57(0.73)$ & 5.00 & 1.00 & 4.00 & $22(12.9)$ & $25(14.7)$ & $123(72.4)$ \\
\hline Professional time & $3.48(0.63)$ & 5.00 & 2.00 & 3.00 & $17(10.0)$ & $61(35.9)$ & $92(54.1)$ \\
\hline Professional environment & $3.48(0.63)$ & 5.00 & 1.50 & 3.50 & $18(10.6)$ & $32(18.8)$ & $120(70.6)$ \\
\hline Delivery of care & $3.45(0.60)$ & 4.67 & 2.00 & 2.67 & $13(7.6)$ & $68(40.0)$ & $89(52.4)$ \\
\hline Patient relations & $3.42(0.61)$ & 4.80 & 1.40 & 3.40 & $13(7.6)$ & $73(42.9)$ & $84(49.4)$ \\
\hline Overall professional satisfaction & $3.28(0.60)$ & 4.86 & 1.14 & 3.72 & $21(12.4)$ & $85(50.0)$ & $64(37.6)$ \\
\hline Stress & $2.66(1.01)$ & 5.00 & 1.00 & 4.00 & $95(55.9)$ & $30(17.6)$ & $45(26.5)$ \\
\hline Income & $2.56(0.68)$ & 4.20 & 1.00 & 3.20 & $80(47.1)$ & $78(45.9)$ & $12(7.1)$ \\
\hline Personal time & $2.39(0.97)$ & 5.00 & 1.00 & 4.00 & $110(64.7)$ & $29(17.1)$ & $31(18.2)$ \\
\hline
\end{tabular}

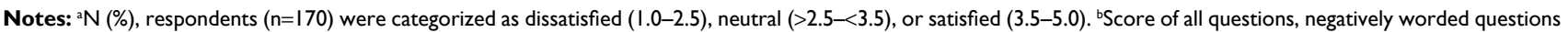
were reverse-coded so the higher score represented higher satisfaction.

Table 3 reports only significant differences observed based on independent $t$-tests and ANOVA. Significant differences in total career score and several factors were found based on gender, working hours per week, and years in practice. Female dentists $(p=0.01)$, working $21-40$ hours per week $(p<0.01)$, and years in practice $\leq 5$ years $(p=0.03)$ had significantly higher total career scores. Dentists who had experience in practice $\leq 5$ years also had higher scores of factors of professional relations $(p<0.01)$, respect $(p=0.03)$, and overall professional satisfaction $(p=0.04)$. Subjects who had 21-40 working hours per week had higher scores of factors of patient relations $(p=0.02)$, personal time $(p<0.01)$, professional environment $(p=0.01)$, respect $(p=0.04)$, and overall professional satisfaction $(p=0.02)$. In addition, female dentists had higher scores of factors of personal time $(p=0.01)$, professional environment $(p<0.01)$, and overall professional satisfaction $(p=0.04)$.

The effect of demographic and practice characteristics on total career score was evaluated by a stepwise-regression analysis (Table 4). Results showed that working hours per week and gender were significant predictors of total career score. Table 5 displays the stepwise-regression analysis focused on predicting the overall professional satisfaction subscale score using other subscales of the CDSS. Four subscales significantly predicted the overall professional satisfaction subscale score: respect, delivery of care, income, and patient relations.

\section{Discussion}

To contextualize this study, it is critically important to have an overview of the professional lives of dentists in China. A majority of dentists work full time in public dental hospitals, and most of the hospitals are in medium to large size cities. Dental hospitals with the highest reputations are usually affiliated with dental schools. Similar to dentists in other countries such as the USA, Chinese dentists working in those hospitals have considerably demanding work responsibilities including developing/teaching didactic classes, conducting research, mentoring dental students, and providing direct care to their own patients. Such a demanding work load often necessitates working 50 hours week or more. The hospitals are also open all year-around including weekends and holidays. Dentists and their supportive staff team members are hired by the hospital human resources office under different kinds of contracts, with dentist salaries paid by the hospital. In general, the income for dentists in China is in the upper third of all occupations; and some dentists earn additional income by treating their own patients. The dental board examination in China is only designed for general dentists, and a universal general dental license is issued after passing the examination. There are specialty training programs for dentists who want to practice as specialists. Patient referrals occur when dentists evaluate the case as complex and beyond the scope of their clinical skills. Dentists fulfill a variety of leadership functions, including leading the direct provision of chairside dental care, organizing clinical operations, and likely serving over the course of a career in some formal role as a program director or department director or, possibly, dean.

Career satisfaction among dentists in China has been brought into focus in recent years since health care reform is raising new concerns about relationships among public hospitals, dentists, and patients. The initial goal of this study was to investigate the level and distribution of job satisfaction 
Table 3 Independent $t$-test for comparisons with two variables and ANOVA for comparisons with three variables

\begin{tabular}{|c|c|c|c|c|c|c|}
\hline Subcategories & Variables & Number & Mean (SD) & $t^{a}$ or $\mathbf{S S}^{\mathrm{b}}$ & df & $p$-value \\
\hline \multirow[t]{10}{*}{ Total career score } & \multicolumn{6}{|l|}{ Gender } \\
\hline & Male & 64 & $119.36(15.19)$ & & & \\
\hline & Female & 106 & $125.40(14.55)$ & 2.58 & 168.00 & $0.0 I^{*}$ \\
\hline & \multicolumn{6}{|c|}{ Working hours per week } \\
\hline & $21-40$ & 74 & I27.07 (I2.7I) & & & \\
\hline & $\geq 40$ & 90 & $119.83(16.42)$ & 3.18 & 161.45 & $0.00 *$ \\
\hline & \multicolumn{6}{|c|}{ Years of practice } \\
\hline & $\leq 5$ & 83 & I25.83 (I2.64) & & & \\
\hline & $6-10$ & 45 & II 8.58 (I8.09) & & & \\
\hline & $\geq \mathrm{II}$ & 42 & $122.64(14.97)$ & $382|4.4|$ & 169.00 & $0.03^{*}$ \\
\hline Professional & Years of pr & & & & & \\
\hline \multirow[t]{3}{*}{ relations } & $\leq 5$ & 83 & $3.95(0.78)$ & & & \\
\hline & $6-10$ & 45 & $3.49(1.12)$ & & & \\
\hline & $\geq I 1$ & 42 & $3.42(0.96)$ & 153.15 & 169.00 & $0.00 *$ \\
\hline \multirow[t]{3}{*}{ Patient relations } & \multicolumn{6}{|c|}{ Working hours per week } \\
\hline & $21-40$ & 74 & $3.54(0.56)$ & & & \\
\hline & $\geq 40$ & 90 & $3.31(0.65)$ & 2.38 & 162.00 & $0.02 *$ \\
\hline \multirow[t]{6}{*}{ Personal time } & Gender & & & & & \\
\hline & Male & 64 & $2.13(0.99)$ & & & \\
\hline & Female & 106 & $2.54(0.93)$ & 2.76 & 168 & $0.01 *$ \\
\hline & \multicolumn{6}{|c|}{ Working hours per week } \\
\hline & $21-40$ & 74 & $2.64(0.87)$ & & & \\
\hline & $\geq 40$ & 90 & $2.18(1.02)$ & 3.05 & 162.00 & $0.00 *$ \\
\hline Professional & Gender & & & & & \\
\hline \multirow[t]{5}{*}{ environment } & Male & 64 & $3.28(0.67)$ & & & \\
\hline & Female & 106 & $3.59(0.58)$ & 3.22 & 168 & $0.00 *$ \\
\hline & \multicolumn{6}{|c|}{ Working hours per week } \\
\hline & $21-40$ & 74 & $3.63(0.56)$ & & & \\
\hline & $\geq 40$ & 90 & $3.36(0.67)$ & 2.79 & 162.00 & $0.01 *$ \\
\hline \multirow[t]{7}{*}{ Respect } & \multicolumn{6}{|c|}{ Working hours per week } \\
\hline & $21-40$ & 74 & $3.70(0.59)$ & & & \\
\hline & $\geq 40$ & 90 & $3.46(0.67)$ & 2.13 & 159.25 & $0.04 *$ \\
\hline & \multicolumn{6}{|c|}{ Years of practice } \\
\hline & $\leq 5$ & 83 & $3.71(0.6 I)$ & & & \\
\hline & $6-10$ & 45 & $3.37(0.89)$ & & & \\
\hline & $\geq 11$ & 42 & $3.52(0.7 I)$ & 88.83 & 169.00 & $0.03 *$ \\
\hline Overall & Gender & & & & & \\
\hline professional & Male & 64 & $3.16(0.67)$ & & & \\
\hline \multirow[t]{8}{*}{ satisfaction } & Female & 106 & $3.35(0.55)$ & 2.03 & 168 & $0.04^{*}$ \\
\hline & \multicolumn{6}{|c|}{ Working hours per week } \\
\hline & $21-40$ & 74 & $3.40(0.48)$ & & & \\
\hline & $\geq 40$ & 90 & $3.19(0.69)$ & 2.32 & 158.33 & 0.02 \\
\hline & \multicolumn{6}{|c|}{ Years of practice } \\
\hline & $\leq 5$ & 83 & $3.39(0.48)$ & & & \\
\hline & $6-10$ & 45 & $3.11(0.70)$ & & & \\
\hline & $\geq 11$ & 42 & $3.23(0.68)$ & 61.56 & 169.00 & $0.04^{*}$ \\
\hline
\end{tabular}

Notes: alndependent $t$-test. ${ }^{b} A N O V A .{ }^{*} p \leq 0.05$.

Abbreviations: ANOVA, analysis of variance; SD, standard deviation; SS, sum of squares; df, degrees of freedom.

Table 4 Variables predicting total career score based on stepwise regression

\begin{tabular}{llllll}
\hline $\begin{array}{l}\text { Independent } \\
\text { variables }\end{array}$ & B & SE B & $\boldsymbol{\beta}$ & $\boldsymbol{t}$ & $\boldsymbol{p}$-value \\
\hline $\begin{array}{l}\text { Working hours } \\
\text { per week }\end{array}$ & -5.49 & 2.03 & -0.206 & -2.70 & $0.008^{*}$ \\
\begin{tabular}{l} 
Gender \\
\hline
\end{tabular} & -6.35 & 2.37 & -0.204 & -2.68 & $0.008^{*}$ \\
\hline
\end{tabular}

Notes: ${ }^{*} p \leq 0.05 . R^{2}=0.089$, Adjusted $R^{2}=0.078, F=7.763, p=0.001$.

Abbreviation: SE, standard error.
Table 5 Variables predicting overall professional satisfaction based on stepwise regression

\begin{tabular}{llllll}
\hline Subcategories & B & SE B & $\boldsymbol{\beta}$ & $\boldsymbol{t}$ & p-value \\
\hline Respect & 0.26 & 0.06 & 0.31 & 4.13 & $0.000^{*}$ \\
Delivery of care & 0.29 & 0.06 & 0.28 & 4.54 & $0.000^{*}$ \\
Income & 0.16 & 0.05 & 0.18 & 3.40 & $0.001^{*}$ \\
Patient relations & 0.22 & 0.08 & 0.22 & 2.89 & $0.004^{*}$
\end{tabular}

Notes: ${ }^{*} p \leq 0.05 . R^{2}=0.531$, Adjusted $R^{2}=0.531, F=46.78, p=0.000$.

Abbreviation: SE, standard error. 
among young and middle-aged Chinese dentists working in the public hospital. The mean total career score was 123.12 out of $190(64.8 \%)$, and mean overall professional satisfaction subscale score was 3.28 out of 5 . These findings parallel results of other studies conducted in the USA, Australia, South Korea, and Sweden. ${ }^{3,13,14,16,19}$ Although the total career score showed the dentists were generally neutral or satisfied with dentistry, there was considerable variability in satisfaction levels. Respondents were more satisfied with professional relations, staff, respect, professional time, and professional environment. Since the subjects were working in a high-level metropolis public hospital, professional support was sufficient, staff were hired and managed by the hospital, and patients generally respected the reputation of the hospital. Respondents tended to be more dissatisfied with personal time, income, and stress. It could also be explained by the public hospital contracted working model. Dentists surveyed needed to sign working contracts with the hospital and work defined hours per week. The hospital collected professional fees, and dentists were also asked to conduct research in addition to clinical work.

The second goal of this study was to examine differences in satisfaction associated with demographic and practice characteristics of Chinese dentists. Results showed that female dentists, working $<40$ hours per week and practicing $\leq 5$ years were generally more satisfied with dentistry, especially in aspects such as professional relations, professional environment, patient relations, personal time, and respect. The questions asked under these subscales can be found in the Supplementary material. Working hours per week and gender also predicted total career scores, with those working 21-40 hours per week and females enjoying higher total career scores.

Shorter working hours per week may indicate conflictive professional demands such as not enough time to practice dentistry due to other competing work responsibilities; or, shorter hours may indicate lower organizational expectations in certain areas of responsibility expected from other dentists. Conversely, longer working hours may likely point toward high and very demanding organizational expectations. Dentists working $\geq 50$ hours per week may still not be able to fulfill all levels of job responsibilities, potentially resulting in fatigue or burnout and/or compromises in their personal/ family lives.

Two studies in Australia and one study in India indicated that female dentists had higher job satisfaction than male dentists. ${ }^{13,14,17}$ Some other studies conducted in the UK and Turkey reported that male dentists had higher mean career satisfaction scores than female dentists. ${ }^{16,10}$ However, other studies found no differences in job satisfaction between genders. ${ }^{11,12,20}$ In our study, there were more young and middle-aged female dentists working in the public hospital, consistent with the previous study showing the worldwide upward trend in female dentists. ${ }^{21}$ One study showed females, on the average, rate caring or helping motives more highly than do males. ${ }^{22}$ It was true that childrearing and family responsibilities greatly impact females' working life and that female dentists are more likely to take a career break. The higher job satisfaction scores in female dentists surveyed may also be explained by more personal time and relatively long maternity leave, which was offered by the hospital. In China, males are culturally often expected to bear more responsibilities at work than their female peers, and may potentially also assume more leadership roles.

In contrast to our findings, several previous studies indicated that older dentists were more satisfied or less depressed with dentistry. ${ }^{12,14,17,20,23}$ Since this study only focused on early and mid-career dentists, $48.8 \%$ of the respondents had practice experience $\leq 5$ years. Compared to countries such as the USA, dental education in China is much less expensive and young Chinese dentists usually do not have significant student loans and the associated financial stress of making sizable student loan payments. Most of the younger dentists surveyed, finished the graduate school programs in the same hospital and still kept the professional relationship with their advisors. This might have provided greater professional support than older dentists who did not have advisors in the same hospital. In addition, young dentists beginning their careers in an advanced hospital face intense competition, and may, therefore, have greater motivation to perform well and fulfill their dreams. However, after several years in practice, dentists take on increased responsibilities both from work and family, and could have somewhat waning passions in their careers.

The majority of the subjects in our study worked $\geq 40$ hours per week $(52.9 \%)$, which was longer than the results reported by some other studies conducted in the USA and the UK, but was shorter than one South Korean study. $3,16,20$ Increasing working hours can increase the risk of burnout, anxiety, and loneliness. ${ }^{12}$ Longer working hours also means less personal time and less freedom of a working schedule, contributing to lower job satisfaction.

The final goal of this study was to initiate discussions about program and policy implications for improving job satisfaction. Our study indicated that the factors of respect, delivery of care, income, and patient relations were related to overall professional satisfaction. These findings may suggest 
a need to offer more courses on patient management in dental schools because dental students get their knowledge first from dental education and tend to implement work habits learned in school in their future careers. The results may also suggest a need to offer early and mid-career dentists, hospital managers, and health care policy makers courses about practice management to define the standard of dental care and other policies. Salary structures to reward those working extended hours is another potential policy implication. Developing and implementing strategies to create a more respectful working environment could also improve job satisfaction among dentists in China.

Dentists are considered as leaders at work. Some of the dentists we surveyed are department directors and a few of them will become directors soon. In general, leaders with higher career satisfaction will foster positive work climates and develop hopeful career tracks through role modeling and mentoring. Total career scores and overall professional satisfaction scores were significantly different based on years of practice, with the lowest scores for dentists with 6-10 years of experience. Further research would have to verify and define this finding. Lower overall professional satisfaction for dentists in the 6- to 10-year career range may result from increasing professional responsibilities in both management and research in addition to patient care. Another key finding with leadership implications is that the professional relations subscale scores showed this alarming trend-scores decreased over the career span $\leq 5$ years (3.95), 6-10 years (3.49), and $\geq 11$ years (3.42). The items making up this subscale were "There is an insufficient number of specialists (more experienced dentists) to whom I can refer patients" and "I have high quality specialists (more experienced dentists) to whom I can refer patients." Arguably, scores for professional relations would increase over time, not decrease. There may be underlying organizational or professional leadership issues at play causing this drop in scores across the career span, particularly in view of the respondents working in a hospital setting alongside other dentists. Culturally, mid-career, older dentists may be less likely to seek referrals for patient care as a part of "face-saving." In addition, the absence of official specialty certification in the Chinese health care system may also result in lower professional relations scores for midcareer, older dentists.

Several limitations of this study need to be mentioned. The online survey utilized in this study included no open-ended questions. And, obviously, no direct observations within the hospital or interviews with dentists were conducted. Multiple methods of data gathering would provide much more detailed, richer findings. As this study is based on a cross-sectional sample, causality of any associations may potentially be called into question. The subjects included only a limited sample of early to mid-career dentists working in a highlevel metropolitan public hospital; thus, findings obviously have limited generalizability. For example, the results may not apply to later career dentists. Furthermore, respondents were not queried about their specific leadership roles, and these roles could clearly impact the hours worked per week and the various dimensions of job satisfaction. The adjusted response rate of this study was $47.4 \%$, and this could have skewed the results. As a group, those choosing to complete the survey could have had generally higher or lower levels of job satisfaction. Nonetheless, recently published similar studies reported response rates for health care professionals including dentists, of $35 \%-68 \%$, and thus the response rate in this study may be considered acceptable. ${ }^{24}$

\section{Conclusion}

For early and mid-career Chinese dentists working in a metropolitan public hospital, total career satisfaction was judged to be good overall. Professional relations, helpful staff, and respect were the most satisfied factors, whereas lack of personal time, low income, and heavy stress were the least satisfied factors. Overall job satisfaction showed a high correlation with respect, delivery of care, income, and patient relations. Significantly higher job satisfaction scores were predicted based on gender (females being higher) and working hours $21-40$ hours per week (vs $>40$ hours per week). Courses focused on practice management could be designed for dental students and dentists. Policies defining the standard of dental care and increasing dentists' income need to be made; strategies improving respectful working environment and reducing stress are also suggested. Future studies exploring the career satisfaction of Chinese dentists would build upon this study by: including a larger sample size, involving more hospitals in other regions with varying demographics such as population, investigating how leadership roles impact job satisfaction, and utilizing other feasible multiple methods such as observation and interviewing.

\section{Acknowledgments}

We thank Dr Yong Jiang and Dr Tongkai Xu from the Peking University School and Hospital of Stomatology for their support in collecting data for this project.

\section{Disclosure}

The authors report no conflicts of interest in this work. 


\section{References}

1. Shugars DA, DiMatteo MR, Hays RD, Cretin S, Johnson JD. Professional satisfaction among California general dentists. J Dent Educ. 1990;54(11):661-669.

2. Balasubramanian M, Spencer AJ, Short SD, Watkins K, Chrisopoulos S, Brennan DS. Job satisfaction among 'migrant dentists' in Australia: implications for dentist migration and workforce policy. Aust Dent J. 2016;61(2):174-182.

3. Shugars DA, Hays RD, DiMatteo MR, Cretin S. Development of an instrument to measure job satisfaction among dentists. Med Care. 1991;29(8):728-744.

4. Roth SF, Heo G, Varnhagen C, Glover KE, Major PW. Job satisfaction among Canadian orthodontists. Am J Orthod Dentofacial Orthop. 2003;123(6):695-700.

5. Roth SF, Heo G, Varnhagen C, Major PW. The relationship between occupational stress and job satisfaction in orthodontics. Am J Orthod Dentofacial Orthop. 2004;126(1):106-109.

6. Humphris G, Peacock L. Occupational stress and job satisfaction in the community dental service of north Wales: a pilot study. Community Dent Health. 1993;10(1):73-82.

7. Harris RV, Ashcroft A, Burnside G, Dancer JM, Smith D, Grieveson B. Facets of job satisfaction of dental practitioners working in different organisational settings in England. Br Dent J. 2008;204(1):E1; discussion 16-17.

8. Nikolovska J, Mancevska S, Kapusevska B, Popovska L, Mindova S. An assessment of career satisfaction among Macedonian dentists. Pril (Makedon Akad Nauki Umet Odd Za Med Nauki). 2014;35(1):255-261.

9. Gorter RC, te Brake JH, Eijkman MA, Hoogstraten J. Job resources in Dutch dental practice. Int Dent J. 2006;56(1):22-28.

10. Sur H, Hayran O, Mumcu G, Soylemez D, Atli H, Yildirim C. Factors affecting dental job satisfaction: a cross-sectional survey in Turkey. Eval Health Prof. 2004;27(2):152-164.

11. Goetz K, Campbell SM, Broge B, Dorfer CE, Brodowski M, Szecsenyi J. The impact of intrinsic and extrinsic factors on the job satisfaction of dentists. Community Dent Oral Epidemiol. 2012;40(5):474-480.
12. Puriene A, Aleksejuniene J, Petrauskiene J, Balciuniene I, Janulyte V. Self-perceived mental health and job satisfaction among Lithuanian dentists. Ind Health. 2008;46(3):247-252.

13. Luzzi L, Spencer AJ. Job satisfaction of the oral health labour force in Australia. Aust Dent J. 2011;56(1):23-32.

14. Luzzi L, Spencer A, Jones K, Teusner D. Job satisfaction of registered dental practitioners. Aust Dent J. 2005;50(3):179-185.

15. Ayers KM, Thomson WM, Rich AM, Newton JT. Gender differences in dentists' working practices and job satisfaction. J Dent. 2008;36(5):343-350.

16. Jeong SH, Chung JK, Choi YH, Sohn W, Song KB. Factors related to job satisfaction among South Korean dentists. Community Dent Oral Epidemiol. 2006;34(6):460-466.

17. Kaipa S, Pydi SK, Kumar RVSK, Srinivasulu G, Darsi VRK, Sode M. Career satisfaction among dental practitioners in Srikakulam, India. J Int Soc Prev Community Dent. 2015;5(1):40-46.

18. Saekel R. China's oral care system in transition: lessons to be learned from Germany. Int J Oral Sci. 2010;2(3):158-176.

19. Ordell S, Söderfeldt B, Hjalmers K, Berthelsen H, Bergström K. Organization and overall job satisfaction among publicly employed, salaried dentists in Sweden and Denmark. Acta Odontol Scand. 2013;71(6):1443-1452.

20. Gilmour J, Stewardson D, Shugars DA, Burke F. An assessment of career satisfaction among a group of general dental practitioners in Staffordshire. Br Dent J. 2005;198(11):701-704.

21. Pallavi S, Rajkumar G. Professional practice among woman dentist. J Int Soc Prev Community Dent. 2011;1(1):14-19.

22. Scarbecz M, Ross JA. Gender differences in first-year dental students' motivation to attend dental school. J Dent Educ. 2002;66(8): 952-961.

23. Wells A, Winter P. Influence of practice and personal characteristics on dental job satisfaction. J Dent Educ. 1999;63(11):805-812.

24. Cook JV, Dickinson HO, Eccles MP. Response rates in postal surveys of healthcare professionals between 1996 and 2005: an observational study. BMC Health Serv Res. 2009;9(1):160. 


\section{Supplementary material}

\section{Chinese Dentist Satisfaction Survey}

Note that negatively worded questions are underlined here but were not underlined in the actual survey administered to research participants.

This study focuses on job satisfaction among dentists in Peking University School of Stomatology. The following survey has been adapted from the Dentist Satisfaction Survey (DSS) (Shugars et al 1990), ${ }^{1}$ one of the most comprehensive and utilized measures of job satisfaction in dentistry. Permission to use the DSS has been granted from Dr. Shugars.

Gender: Male/Female

\section{Date of Birth (YYYY/MM/DD):}

Hometown: Urban area/Rural area

Highest Education: Bachelor/Master's/Doctor's (PhD)

\section{Year of Graduation:}

Specialty training: Yes/No

Years of practice: $\leq 5$ years/6-10 years/11-15 years/ $\geq 16$ years

Working hours per week: $\leq 20$ hours/ $21-40$ hours $\geq 40$ hours

Directions: For each statement listed below, circle the one number that represents your level of agreement. Use the following scale:

$5=(\mathrm{SA})$ Strongly agree

$4=(\mathrm{A})$ Agree

$3=(\mathrm{N})$ Neither agree nor disagree

$2=(\mathrm{D})$ Disagree

$1=(\mathrm{SD})$ Strongly Agree

Staff

8. The quality of my auxiliary personnel is lacking.

14. The work performance of my auxiliaries is outstanding.

2. The office staff works well together.

Income

29. My income allows me to provide very well for my family.

4. The income I receive from this job is much lower than I desire.
33. The income that I receive from my job is most satisfactory for my needs.

7. My income is not nearly as high as that of other dentists.

30. My income compares favorably to that of other professionals.

Professional Relations

32. There is an insufficient number of specialists (more experienced dentists) to whom I can refer patients.

9. I have high quality specialists (more experienced dentists) to whom I can refer patients.

Professional Time

26. I have very little time to keep abreast of advances in the field of dentistry.

18. I have enough time to improve my clinical skills.

19. I have been able to incorporate into my job the technological changes occurring in dentistry.

5. I have sufficient time for professional contacts with colleagues.

3. I have very limited opportunity to discuss difficult cases with colleagues.

Delivery of Care

10. I am skilled at dealing with my patients' dental problems.

21. I am able to practice dentistry the way I want to.

16. I lack opportunities to provide quality care.

Patient Relations

13. I find my relationships with patients satisfying.

36. Relating to patients is very frustrating for me. (Dealing with the patient-dentist relationship is a stressful issue to me.)

27. The quality of interpersonal care I provide is very high.

20. I enjoy helping patients.

12. I am worried about being attacked by patients.

Personal Time

35. I have enough time available for my personal life and leisure activities.

31. I have too little time available for leisure.

Professional Environment 
22. The threat of malpractice has caused me to significantly alter the way I practice.

25 . I will buy malpractice insurance if there will be that kind of insurance in the future.

\section{Respect}

\section{I do not get the respect that I deserve.}

17. I feel quite proud to be a dentist.

Stress

\section{Dentistry is a very stressful profession.}

1. Doing dentistry is very stressful for me.

Overall Professional Satisfaction

28. Dentistry fulfills my current career aspirations.
24. Knowing what I know now, I would make the same decision to go into dentistry again.

34. If my child were interested in dentistry, I would encourage $\mathrm{him} /$ her to pursue a dental career.

11. I appear more satisfied with my job than I really am.

38. I am very likely to change careers within 5 years.

6. Dentistry is the place where I can make my best contribution.

37. Overall, I am extremely satisfied with my career.

\section{Reference}

1. Shugars DA, DiMatteo MR, Hays RD, Cretin S, Johnson JD. Professional satisfaction among California general dentists. J Dent Educ. 1990;54(11):661-669.
Journal of Healthcare Leadership

\section{Publish your work in this journal}

The Journal of Healthcare Leadership is an international, peer-reviewed, open access journal focusing on leadership for the health profession. The journal is committed to the rapid publication of research focusing on but not limited to: Healthcare policy and law; Theoretical and practical aspects of healthcare delivery; Interactions between healthcare and society and evidence-based practices;

\section{Dovepress}

Interdisciplinary decision-making; Philosophical and ethical issues; Hazard management; Research and opinion for health leadership; Leadership assessment. The manuscript management system is completely online and includes a very quick and fair peer-review system. Visit http://www.dovepress.com/ testimonials.php to read real quotes from published authors.

Submit your manuscript here: http://www.dovepress.com/journal-of-healthcare-leadership-journal 